\title{
RIQUEZA DE RESULTADOS EN LA APLICACIÓN DEL MÉTODO DE ESPECIFICIDADES ${ }^{1}$
}

Concepción Otaola Olano

UNED

\section{INTRODUCCIÓN}

Con el estudio lexicométrico que se presenta, queremos defender la idea de que algunos tratamientos estadísticos de los textos, asistidos por ordenador, pueden proporcionar una gran riqueza interpretativa en el nivel semántico. Para alcanzar ese objetivo, nos hemos propuesto aplicar el método lexicométrico de las especificidades en un corpus de prensa contemporánea española. Los resultados obtenidos de dicha aplicación van a proporcionar la posibilidad de detectar una diferenciación en la posición ideológica de los diversos grupos de opinión, representados en la prensa del momento, así como los cambios acaecidos en el comportamiento discursivo de los mismos, desde la perspectiva de la evolución cronológica del componente discursivo que resultará, en gran medida, acorde con la estrategia política de los acontecimientos.

1 El presente estudio es una ampliación modificada de la comunicación que, con el mismo título, presentamos en «JADT 1995, 3rd. International Conference on Statistical Analysis of Textual Data», Roma, 1995. 


\section{MÉTODO, CORPUS Y METODOLOGIA}

El método de las especificidades fue desarrollado en el Laboratorio de St.Cloud (París) por P. Lafon, quien en 1977 lo plasmó en su artículo «Variabilité de la fréquence des formes dans un corpus» ${ }^{2}$ Posteriormente ha sido aplicado por numerosos estudiosos, como se puede apreciar en la vasta bibliografía existente sobre el tema.

Recurrre P. Lafon a una técnica estadística con objeto de estudiar la variabilidad de la frecuencia de las formas, en el seno de un corpus dividido en varias partes.

A tal fin, adopta de la estadística las fórmulas de la distribución hipergeométrica que, según Lafon ${ }^{3}$, «sont exactement adaptées à la population discrète des occurrences de vocabulaire, et valides pour toute la gamme des fréquences rencontrées» [son exactamente adaptadas a la población discreta de las ocurrencias de vocabulario, y válidas para toda la gama de frecuencias encontradas.] El cálculo hipergeométrico se lleva a cabo por fórmulas matemáticas ${ }^{4}$ y se tienen en cuenta la frecuencia total de la forma en el corpus y la subfrecuencia de la misma en la parte del corpus considerada.

Este método probabilístico permite clasificar las formas lexicales y funcionales de un texto en tres diferentes grupos: las ultraempleadas (especifidad positiva), las subempleadas (especificidad negativa) y las formas banales (vocabulario de base). En suma, con este método en que se emiten juicios de probabilidad del empleo de las formas, se pueden descubrir desde las formas significativamente ultraempleadas por una variable (por ejemplo, un emisor) hasta las subempleadas. Estas variaciones de empleos pueden tener una explicación de muy diverso orden: linguístico, estilístico, histórico o sociológico.

Siguiendo los postulados de M.Tournier (1980) sobre la homogeneidad de las situaciones de enunciación, así como los de A.Salem (1987) en lo que se refiere al calibraje del corpus en partes que no difieran demasiado en su extensión, hemos llegado a formar un corpus cerrado y equilibrado en cuanto a la semejanza en la longitud de las partes que lo componen. Este corpus se ha constituido con las crónicas de información y editoriales o artículos de opinión aparecidos en la prensa y referidos a las manifestaciones o situaciones

2 Se publicó en Travaux de lexicométrie et de lexicologie politique. Una nueva versión apareció en la revista Mots, 1 (1980) pp. 127-165, a la que nos referiremos constantemente.

3 Op. cit. Mots, 1, p. 128.

- Estas fómulas fueron explicitadas por P. Lafon en el artículo anteriormente mencionado. Una exposición menos técnica se puede encontrar en el artículo de Marie-René Guyard «Spécificités d'auteurs dans Le surréalisme au senvice de la Révolutionw. Mots, 2, marzo 1981, pp. 95-122. 
conflictivas que se desarrollaron en la vía pública, en Melilla, protagonizadas por distintos actores socio-políticos durante el año 1985-86. Estas situaciones surgieron a raíz de la posible aplicación de la Ley de Extranjería sobre los musulmanes afincados en dicha ciudad, ubicada en el norte del continente africano y limítrofe con Marruecos.

En la selección de las tomas, que giran en torno a esos acontecimientos puntuales en favor o en contra de dicha Ley, se ha tenido en cuenta no sólo el hecho de que fuesen recogidos o comentados por todos los diarios seleccionados, sino que también fuesen importantes, tanto por el número de participantes en los mismos como por su repercusión en el conflicto.

Para la constitución del corpus ${ }^{5}$ se han tenido en cuenta dos variables: a) los emisores y b) la cronología. Consecuentemente, se ha organizado el corpus en dos bloques, conformados como explicamos a continuación.

Desde la variable de los emisores se ha practicado una partición del corpus en 7 EMISORES. Éstos se han seleccionado dentro de la pluralidad ideologica de la prensa contemporánea del momento, teniendo en cuenta la heterogeneidad y la representatividad. Los emisores son periódicos diarios tanto de difusión nacional (El País, ABC, El Alcázar, Diario 16) como local (Melilla Hoy) y publicaciones como el semanario Mundo Obrero y el conjunto de escritos emitidos por lo que hemos convenido en llamar Comunidad Musulmana 6 .

En la perspectiva diacrónica o cronológica, se ha efectuado una partición del corpus en tres etapas dentro del año en que se han fijado los límites. Se han seleccionado, en cada una de ellas, los acontecimientos más significativos, pero teniendo siempre presente el aspecto de equilibrio cuantitativo. Esta es la variable 3 ETAPAS.

\section{La longitud total del corpus asciende a 66.323 ocurrencias.}

En este corpus estudiamos las especificidades positivas (o ultraempleo) y negativas (o subempleo) de las formas y poliformas, dentro del parámetro del programa establecido del 0.05 , es decir, que el umbral de frecuencia será el $5 \%$ de probabilidades. Por consiguiente, será considerada de especificidad positiva, en

3 Es de destacar la valiosa participación de Lydia Romeu en la constitución del corpus, especialmente en la consecución del equilibrado cuantitativo del mismo, asf́como en la total supervisión en la aplicación de los programas lexicométricos. Colaboraron también en la localización de algunos textos los profesores Marina Fernández-Lagunilla y Nicolás Campos.

- Dada la necesidad imprescindible de que figurase la perspectiva de los directamente afectados por la aplicación de la Ley de Extranjeria, origen próximo de todo el conflicto, y estando forzados por el hecho de que las organizaciones musulmanas no contaban con un órgano periódico de difusión, hemos recogido una serie de articulos de sus líderes y de comunicados de prensa firmados por diferentes organizaciones musulmanas y con distintas posiciones ante dicha Ley. 
una parte del corpus, la forma en que la suma de las probabilidades calculadas con el modelo hipergeométrico para los valores iguales o superiores a la subfrecuencia constatada sea inferior al $5 \%$. Si la suma de las probabilidades calculadas para los valores iguales o inferiores a la subfrecuencia constatada es inferior al 5\%, será considerada como especificidad negativa. No trataremos las formas «banales» en que la subfrecuencia no entra en ninguno de los casos anteriores.

El estudio se efectuará en análisis contrastivo, es decir, comparando conjuntamente y al tiempo los resultados de todos los emisores así como, en su caso, de las tres etapas cronológicas. En ocasiones se remitirá a los resultados obtenidos de las especificidades en cada emisor, en que se desgaja la especificidad lexical de cada parte, con objeto de corroborar o precisar el resultado obtenido en el ańlisis conjunto de los siete emisores.

Si bien partimos del análisis de los emisores para concluir con el diacrónico o cronológico, no obstante, en ambas variables del corpus hemos formado pequeñas redes semánticas, siguiendo los pasos de algunos autores en la aplicación de este método. Esta práctica se basa en el reconocimiento de que el vocabulario se estructura en familias con redes de relaciones entre sí. A.Geffroy la defendió y afirmó al respecto «las especificidades no deben ser analizadas aisladamente [...]; se organizan en conjuntos [...]» (1980). La agrupación en campos temáticos se efectuó plenamente en la obra colectiva La parole syndicale (1982). Aunque la constitución de redes conceptuales o temáticas va en detrimento de la exhaustividad y del rigor total, ya que implica cierta arbitrariedad en los agrupamientos, sin embargo, favorece la concentración en los temas que consideramos de mayor interes para nuestro estudio. Por otra parte, es positiva la combinación de la lectura por campos conceptuales con la lectura por locutores, pues mitiga la inclinación hacia el conocimiento que ya tenemos de los emisores, objetivándolo y relativizándolo con los resultados obtenidos.

Nos centraremos, principalmente, en los siguientes aspectos:

- Plano nominal del sistema designativo de los sujetos socio-políticos de los acontecimientos.

- Red semántica del aspecto reivindicativo.

- Red semántica del aspecto patriótico.

- Manifestación de la alteridad.

\section{Contexto SOcio-político}

El día 1 de julio de 1985 se promulgó la Ley Orgánica 7/1985 sobre los Derechos y Libertades de los Extranjeros en España, es decir, la llamada 
comunmente Ley de Extranjería. La posible aplicación de esta ley sobre los marroquíes asentados e incluso nacidos en Ceuta y Melilla, ciudades españolas limítrofes con Marruecos, acarreaba una serie de consecuencias negativas para esta población, que podían desembocar en la expulsión del territorio español de miles de personas de este colectivo.

Esta población marroquí representaba alrededor de la tercera parte de la población local (se hablaba de $\mathbf{2 7 . 0 0 0}$ marroquíes afincados en Melilla) pero, se encontraba en una situación legal de irregularidad, pues s6lo unos 3.000 estaban en posesión de la nacionalidad española, a pesar de que, en algunos casos, se trataba de familias enteras que llevaban hasta tres o más generaciones asentadas en Melilla.

A la discriminación de estos marroquíes en aspectos políticos y sociales -discriminación que fue reconocida posteriormente y públicamente por diversas autoridades locales y del gobierno español- se añadía la discriminación legal recogida en la Ley de Extranjería que no contemplaba su situación y, por tanto, los consideraba como kextranjeros».?

La publicación de esta Ley supuso la chispa del estallido de un periodo de protestas y manifestaciones en esas dos ciudades y, especialmente, en Melilla, con la confrontación de las dos comunidades más numerosas, que hemos convenido en llamar «comunidad musulmana y «comunidad cristiana», a pesar de que la denominación más frecuente en la Epoca, como veremos posteriormente, era «musulmanes» y «cristianos». ${ }^{8}$

Por razones de espacio no es posible una exposición pormenorizada de los acontecimientos sobrevenidos en este año pero, puesto que estamos marcados

' Once anos después, el 29 de marzo de 1996, ha tenido lugar en Melilla una marcha, convocada por Coalición por Melilla e integrada por unos 6.000 kmelillenses de origen bereberm bajo el lema Contra la marginación y por la justicia social. Aparte de protestar contra la marginación, piden que se concluya el proceso de documentación iniciado hace diez anos. (El Pafs, 31 marzo, 1996).

Con la publicación del Real Decreto 155/1996, de 2 de febrero, por el que se aprueba el Reglamento de ejecución de la Ley Orgánica 7/1985. que sustituye al Real Decreto $1119 / 1986$ de 26 de mayo, se produce un avance en la reforma de la llamada Ley de Extranjeria, especialmente con el capítulo III, art. 52, por el cual los extranjeros pueden obtener el permiso de residencia permanente, cuando hayan residido legalmente y de forma continuada durante seis años en España. Otras novedades de este Reglamento son: la simplificación de los trámites para la obtención de los permisos de residencia y trabajo, la creación de un único documento unificado para los extranjeros residentes y la consideración de la expulsión como medida extraordinaria.

- Todavía hoy, el Delegado del Gobierno en Melilla afirma que el conflicto surgido a raiz del asesinato de un legionario en Melilla, no se trata de un enfrentamiento entre *cristianos y musulmanesw. (El Pais, 16, III, 1996).

- Una exposición más exhaustiva de este contexto político-social apareció publicada en Epos, VI, (1990), 147-175. 
por el hecho de haber realizado una partición cronológica del corpus en tres etapas, vamos a centramos en los acontecimientos políticos y sociales que, en Melilla, perfilan cada una de estas tres etapas.

Primera etapa: El día 23 de noviembre de 1985, miles de musulmanes se manifiestaron en protesta por la prevista aplicación sobre ellos de la Ley de Extranjería. Como réplica, el día 6 de diciembre, se celebró una manifestación o contramanifestación a favor de la Ley. Fue convocada por todos los partidos políticos de Melilla y resultó un acto de afirmación española. Al día siguiente se cerraron los comercios propiedad-de musulmanes.

Segunda etapa: Este periodo intermedio va desde abril hasta junio y gira en torno a una serie de acontecimientos diversos.

A pesar de que en febrero de 1986 se llegó al acuerdo, entre la Administración española y los representantes musulmanes de Ceuta y Melilla, de agilizar la concesión de nacionalidades, no será hasta el mes de agosto cuando se inicie el censo de esta población, paso previo necesario para tal fin. ${ }^{10} \mathrm{El}$ día 9 de abril se produjo una concentración de musulmanes ante el Ayuntamiento para protestar por la lentitud de la tramitación de su documentación.

En junio se celebró una manifestación de cristianos contra el Delegado del Gobierno, quien calificó de legales las elecciones paralelas llevadas a cabo por los musulmanes, difundio un comunicado reconociendo la situación de discriminación e injusticia a que había sido sometida la comunidad musulmana y destituyó al capitán jefe de la Policía Nacional, ordenando también la salida de 24 policías de la ciudad. La situación de crispación y tensión se proyecta en los conflictos entre musulmanes y cristianos así como entre manifestantes y policía.

La última etapa está marcada por el giro que toman las reivindicaciones de los musulmanes. El 6 de noviembre, la comisión de musulmanes de MeliIla acordó romper las negociaciones con la Administración, debido al incumplimiento por parte del Gobierno de los acuerdos alcanzados en febrero pasado, sobre todo en lo que respecta a la concesión de nacionalidades. El líder musulmán, Aomar Mohamedi Dudú, decidió abandonar su cargo de asesor del Ministerio y el colectivo musulmán celebró una asamblea el día 8 del mismo mes. En ella se elaboró un comunicado en el que se declaraba el carácter árabe y musulmán de la ciudad de Melilla y se proclamaba la solidaridad panárabe.

${ }^{10}$ De acuerdo con lo expuesto en la nota 7, parece que, once años después, todavia no se ha concluido el proceso de documentación que también es esencial para la simple obtención del permiso de residencia permanente, previsto en el Reglamento 155/1996 de ejecución de la Ley Orgánica $7 / 1985$. 
Se finaliza esta etapa de nuestro corpus con la celebración de una manifestación del colectivo musulmán contra la Ley de Extranjería. En el transcurso de la misma, el líder musulmán es aclamado y vitoreado, y aprovecha para anunciar su rechazo al documento nacional de identidad provisional, propuesto por el Gobierno para los musulmanes de Ceuta y Melilla que estuviesen tramitando la solicitud de nacionalidad. Destaca el hecho de que, en esta manifestación, uno de los «slogan» más frecuentemente repetido dice asi: «Melilla magrebí, árabe y musulmana».

\section{ANÁlisis de Los RESUltados}

\subsection{Plano nominal del sistema designativo de los sujetos socio-políticos}

Una rápida mirada a los esquemas presentados a continuación (Figuras 1 y 2), nos permite apreciar no sólo la diferencia de empleo de las distintas unidades designativas dependiendo del emisor (variable 7 EMISORES) y de su ideología, sino también la evolución en el tiempo (variable 3 ETAPAS).

En la variable de 7 EMISORES, (Figura 1) debemos destacar que, después del nombre propio de la ciudad, Melilla, es musulmanes la forma nominal de mayor frecuencia (386 ocurrencias) en la lista de especificidades. Señalamos que, en las especificidades por emisor, se aprecia su subempleo en El Alcázar, $A B C$ y Melilla Hoy, aunque en este último emisor se detecta el ultraempleo de la poliforma musulmán de origen marroquí.

Este sustantivo seguido del adjetivo melillense (con morfema -ense que indica lugar de origen), es decir, el sintagma musulmanes melillenses, es ultraempleado por la Comunidad Musulmana, reforzado, a veces, por la presencia de verbos en primera persona del plural con indicación de inclusión. Este es el caso de los enunciados «asamblea de los musulmanes melillenses, que convocamos y celebramos» o «significaría proclamar que los musulmanes melillenses no somos de esta tierra». Estos resultados reflejan la reivindicación de esta comunidad, especialmente al principio del conflicto, de que son españoles pues su lugar de origen es Melilla, es decir, son de Melilla. Incluso llegan a afirmar «somos melillenses" (S+ en Melilla Hoy).

El diario El País presenta una coincidencia con la ideología encontrada en la Comunidad Musulmana al tener como especificidad positiva la unidad melillenses musulmanes en que, curiosamente, se invierten los términos componentes de aquella unidad designativa, es decir, sustantivando melillenses, quizá para enfatizar el hecho de que los musulmanes son de Melilla. 
Plano nominal del. sistema designativo de los sujetos socio-poltticos (VARIABLE 7 EMISORES)

\begin{tabular}{|c|c|c|c|c|c|c|c|}
\hline & $\begin{array}{c}\text { El } \\
\text { País }\end{array}$ & $\begin{array}{c}\text { Melilla } \\
\text { Hoy }\end{array}$ & $\begin{array}{c}\text { El } \\
\text { Alcázar }\end{array}$ & $A B C$ & $\begin{array}{c}\text { Diario } \\
16\end{array}$ & $\begin{array}{l}\text { Mundo } \\
\text { Obrero }\end{array}$ & $\begin{array}{c}\text { Com. } \\
\text { Musul- } \\
\text { mana }\end{array}$ \\
\hline $\begin{array}{l}\text { MUSULMANES (Sustantivo) } \\
\text { - Los musulmanes } \\
\text { - a los musulmanes }\end{array}$ & & S- & S- & s- & & St & \\
\hline MUSULMANES MELILLENSES & & & & & & & St \\
\hline MUSULMANES DE MELILLA & & & s- & & St & & S+ \\
\hline MELLLENSES MUSULMANES & St & & & & & & \\
\hline MELILLENSES DE ORIGEN MARROQUI' & St & & & & & & \\
\hline MUSULMÁN DE ORIGEN MARROQUÍ & & St & & & & & \\
\hline LA POBLACIÓN MUSULMANA & & & & & St & & \\
\hline $\begin{array}{l}\text { MUSULMÁN (-ANA) (Adjetivo) } \\
\text { - Colectivo musulmán de Melilla } \\
\text { - Pueblo musulmán de Melilla } \\
\text { - Comunidad Musulmana }\end{array}$ & & & & & & s- & St \\
\hline MARROQUTES & & s- & St & & & & s- \\
\hline MAGREBIES & & & St & & & & \\
\hline MOROS & & & & & & St & \\
\hline $\begin{array}{l}\text { CRISTLANOS } \\
\text { - Grupos de cristianos } \\
\text { - Manifestanles cristianos } \\
\text { - Coches de cristianos }\end{array}$ & St & & & & & & \\
\hline $\begin{array}{l}\text { CRISTIANO } \\
\text { - Colectivo dominante cristiano } \\
\text { - Espectro cristiano de la ciudad }\end{array}$ & & & & & & & St \\
\hline COLECTIVO (S) & & & s- & S- & & & St \\
\hline
\end{tabular}

St = especificidad positiva en ese emisor. $S$ - = especificidad negativa o subempleo

(FIGURA 1) 
Por el contrario, el subempleo, por parte de El Alcázar, de la poliforma musulmanes de Melilla, unidad que también indica la procedencia de los musulmanes, y el ultraempleo de marroquíes y magrebíes por este emisor, parece reflejo de su no consideración del origen melillense de esta población y, por tanto, de la negativa a reconocerles la condición de españoles. Los denomina «los residentes marroquíes en los territorios españoles de Ceuta y Melilla» o «los marroquíes que viven en nuestro territorio nacional». Por el contrario, en Mundo Obrero este término designa a los habitantes de Marruecos: «partidos políticos marroquíes», kciudadanos marroquíes que viven en Marruecos».

Resulta chocante el ultraempleo de moros por el emisor Mundo Obrero. El hecho se debe a que este semanario quiere plasmar el sentimiento racista existente en la época y recoge declaraciones de melillenses cristianos como las siguientes: «Estos mierdas de moros se van a enterar hoy de quien manda en Melilla» o «Aquí a los moros, siempre se les ha tratado bien, pero que quieran ser españoles ...» 0 «Moros aquí» (pintada colocada sobre un contenedor de basura).

Conocemos que el uso de moro era normal y cotidiano, tanto por parte de los musulmanes como de la comunidad cristiana. Por consiguiente, la ausencia de especificidades positivas en otros diarios parece demostrar su carácter de tabú lexical.

Los términos musulmanes y moros nos evocan inmediatamente su opuesto los cristianos. Esta forma es ultraempleada por El País para referirse a los habitantes de Melilla que no son musulmanes. Por contra, es de especificidad negativa en el emisor individualizado $A B C$. En singular, cristiono, es de especificidad positiva en la Comunidad Musulmana cuando se refieren al colectivo dominante cristiano y al espectro cristiano de la ciudad, en que incluyen «desde el PSME-PSOE hasta los ultrarracistas.»

En la Comunidad Musulmana es ultraempleada su autodesignación como colectivo musulmán de Melilla, mientras que, analizando las especificidades por emisor, sobresale la especificidad negativa de colectivo(s) tanto en $\mathrm{El} \mathrm{Al}$ cázar como en $A B C$. En este último se afina más, resultando subempleada la poliforma el colectivo musulmán.

En la variable 3 ETAPAS (Figura 2) observamos que, si bien la forma musulmanes, analizada en sí misma, aparece como específica positiva tanto en

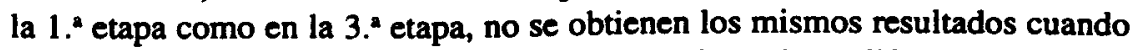
está combinada con el adjetivo melillense. En efecto, las poliformas (los) musulmanes melillenses y (los) musulmanes de (Melilla) son ultraempleadas en la 3." etapa cronológica, hecho que recalca la consideración de la población musulmana como melillenses o pertenecientes a Melilla.

No obstante, un nuevo matiz surge con la aparición de las formas musulmán, árabe y magrebí como hiperespecíficas en la 3." etapa y, por tanto, de especificidad negativa en las otras dos etapas. Estos resultados son consecuen- 
Plano nominal del sistema designativo de los sujetos socio-politicos (VARIABLE 3 ETAPAS)

\begin{tabular}{|c|}
\hline 1.' ETAPA \\
\hline MUSULMANES \\
\hline S- \\
\hline S- \\
\hline S- \\
\hline - Colectivo musulman \\
\hline Musulmin melillense \\
\hline S. \\
\hline LAS) COMUNDADES \\
MUSULMANAS \\
\hline S- \\
\hline S. \\
\hline S- \\
\hline MELLLENSES \\
\hline - De los melillenses melilenses \\
\hline
\end{tabular}

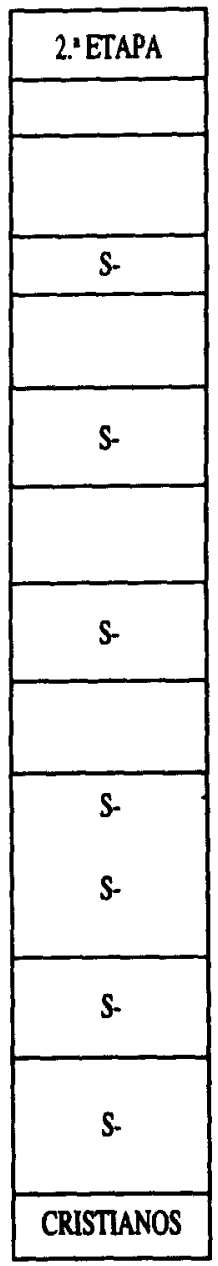

\begin{tabular}{|c|}
\hline 3.' ETAPA \\
\hline MUSULMANES \\
\hline $\begin{array}{l}\text { (LOS) MUSULMANES MELILLENSES } \\
\text { (LOS) MUSULMANES DE (MELILLA) }\end{array}$ \\
\hline MUSULMÁN (Hiperespecifien) \\
\hline $\begin{array}{l}\text { - El colectivo musulmán de Meliila } \\
\text { - El pueblo musulmán de Melilla }\end{array}$ \\
\hline $\begin{array}{l}\text { LA COMUNIDAD MUSULMANA DE } \\
\text { MELULA }\end{array}$ \\
\hline s. \\
\hline $\begin{array}{l}\text { (PUEBLO) MUSULMÁN DE ORIGEN } \\
\text { MARROQUÍ }\end{array}$ \\
\hline $\begin{array}{l}\text { ÁRABE (Hiperespecifica) } \\
\text { - (caricter) Árabe y musulmán } \\
\text { - árabe y musulmán de la ciudad (de Melilla) } \\
\text { los pueblos drabes (Riperespecifica) }\end{array}$ \\
\hline $\begin{array}{l}\text { MAGREBI (Hiperespecífica) } \\
\text { (carácter) árabe musulmán y magrebi de Melilla }\end{array}$ \\
\hline S- \\
\hline S. \\
\hline
\end{tabular}

La aparición de la unidad designativa indica que es especificidad positiva (FIGURA 2)

cia de la evolución ideológica que se ha producido en el desarrollo del conflicto. Así, si bien en la 1.a etapa los musulmanes se consideraban de Melilla y, consecuentemente, españoles, de ahí su exigencia de la nacionalidad española, sin embargo, en la 3. ${ }^{2}$ etapa se siguen considerando de Melilla pero más cerca- 
nos a los pueblos árabes (hiperespecífica en 3.2 etapa), es decir, de origen árabe y magrebí y/o marroquí. Claro ejemplo es su autodenominación como kpueblo musulmán de origen marroquí de Melilla» y su proclamación de $\ll$ Melilla magrebí, árabe y musulmana.»

Tanto la unidad designativa el pueblo musulmán de Melilla como el colectivo musulmán de Melilla aparecen con especificidad negativa en la 1 . $^{\text {a }}$ parte, mientras que son ultraempleadas en la 3." parte. Las poliformas colectivo musulmán y musulmán melillense son ultraempleadas en la $1 .^{2}$ parte y subempleadas en la $2 .$.

El ultraempleo de la forma aislada cristianos, en la $2 .^{a}$ parte cronologica, viene forzado por los incidentes y disturbios protagonizados, en esta época, por los «cristianos» principalmente, hecho que se invierte en la 3.2 etapa en que las manifestaciones son de musulmanes y, consiguientemente, la forma cristianos resultará de especificidad negativa.

\subsection{Red semántica del aspecto reivindicativo.}

Con una primera lectura del agrupamiento semántico de los resultados que aparecen en la lista de especificidades, en la variable 7 EMISORES, podemos conocer no sólo cuáles son las reivindicaciones que se efectúan en estos acontecimientos, sino también quiénes son los solicitantes. Así lo apreciamos gráficamente en la Figura 3. Las formas aparecen presentadas en una escala de mayor a menor frecuencia y según los emisores.

Red SEMANTICA DEL ASPECTO REIVINDICATIVO (VARIABLE 7 EMISORES)

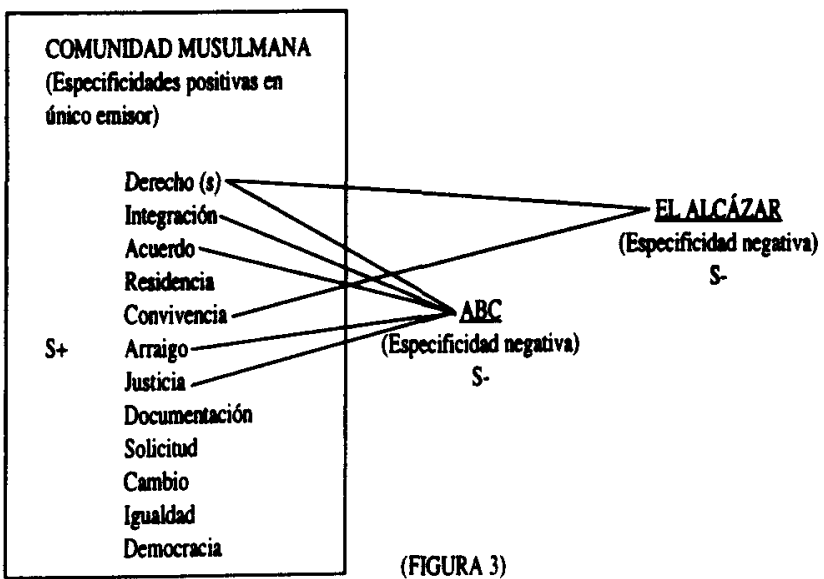


Curiosamente la poliforma la nacionalidad española, designación de una de las aspiraciones de los musulmanes y tema del conflicto, es ultraempleada en El País y Mundo Obrero. Por el contrario, es subempleada en El Alcázar, con una frecuencia de 0 ocurrencias. Una interpretación de estos hechos nos inclina a relacionarlos con los empleos, por este emisor, de las unidades designativas marroquíes y magrebies. La nacionalidad es también de especificidad negativa en $A B C$.

Señalamos que, si bien los acontecimientos que nos ocupan surgieron a raíz de la posible aplicación de la Ley de Extranjería, sin embargo, la poliforma la aplicación de la ley de extranjería es específicamente negativa en Comunidad Musulmana y, ni siquiera la poliforma contra la ley de extranjería resulta específicamente positiva en este emisor, aunque sí en Diario 16.

La evolución de las reivindicaciones de los sujetos socio-políticos así como la intensidad de la solicitud de las mismas y, consecuentemente, la evolución del conflicto, quedan netamente reflejadas en la Figura 4, en que se han colocado las unidades por etapas y según el orden decreciente de aparición en los resultados, por frecuencia.

En dicha figura encontramos varias formas y poliformas hiperespecíficas en las etapas $1^{a}$ y $3^{2}$ que nos van a dar la pauta para localizar el eje en torno al cual giran las reivindicaciones en cada etapa. Así, en la $l^{\text {u }}$ etapa son hiperespecíficas la ley de extranjeria, derechos humanos y la nacionalidad (española). En efecto, en la $l^{\text {* }}$ etapa los musulmanes lucharon por obtener la documentación que acreditase su nacionalidad española ya que ellos se consideraban melillenses y, por tanto, españoles. Por el contrario, en la $3^{\mathbf{a}}$ etapa solicitan (la) doble nacionalidad, la española y la marroquí, y defienden su carácter árabe, ambas unidades hiperespecíficas de esta etapa.

La $2^{a}$ etapa de este periodo se perfila de transición entre las reivindicaciones de la l" etapa y las de la etapa final. La mayoría de las formas y poliformas que manifiestan las reivindicaciones y que son de especificidad positiva de la $1^{2}$ etapa, resultan negativas en la $2^{2}$. El mismo término reivindicación es subempleado en esta etapa. Los pilares que mantienen este periodo se reflejan en las dos formas que manifiestan las preocupaciones del momento entre los ha- 
RED SEMÁNTICA DEL ASPECTO REIVINDICATIVO (VARIABLE 3 ETAPAS)

\begin{tabular}{|l|}
\hline \multicolumn{1}{|c|}{ I.' ETAPA } \\
\hline - NACIONALIDAD (Hiperespecifica) \\
LA NACIONALIDAD ESPANNOLA \\
\hline \multicolumn{1}{|c|}{ S- } \\
\hline $\begin{array}{l}\text { DERECHOS HUMANOS (Hiperespecifica) } \\
\text { - Por los derechos }\end{array}$ \\
\hline - LA LEY DE EXTRANIERfA (Hiperespecifica) \\
- APLICACIÓN(DE LA LEY DE \\
EXTRANJERIA) \\
SÍ A LA LEY DE EXTRANJERIA \\
(Hiperespecífica) \\
- CONTRA LA LEY DE EXTRANJERIA \\
\hline - JUSTICIA \\
\hline - (LA) LIBERTAD \\
\hline \\
\hline \\
\hline
\end{tabular}

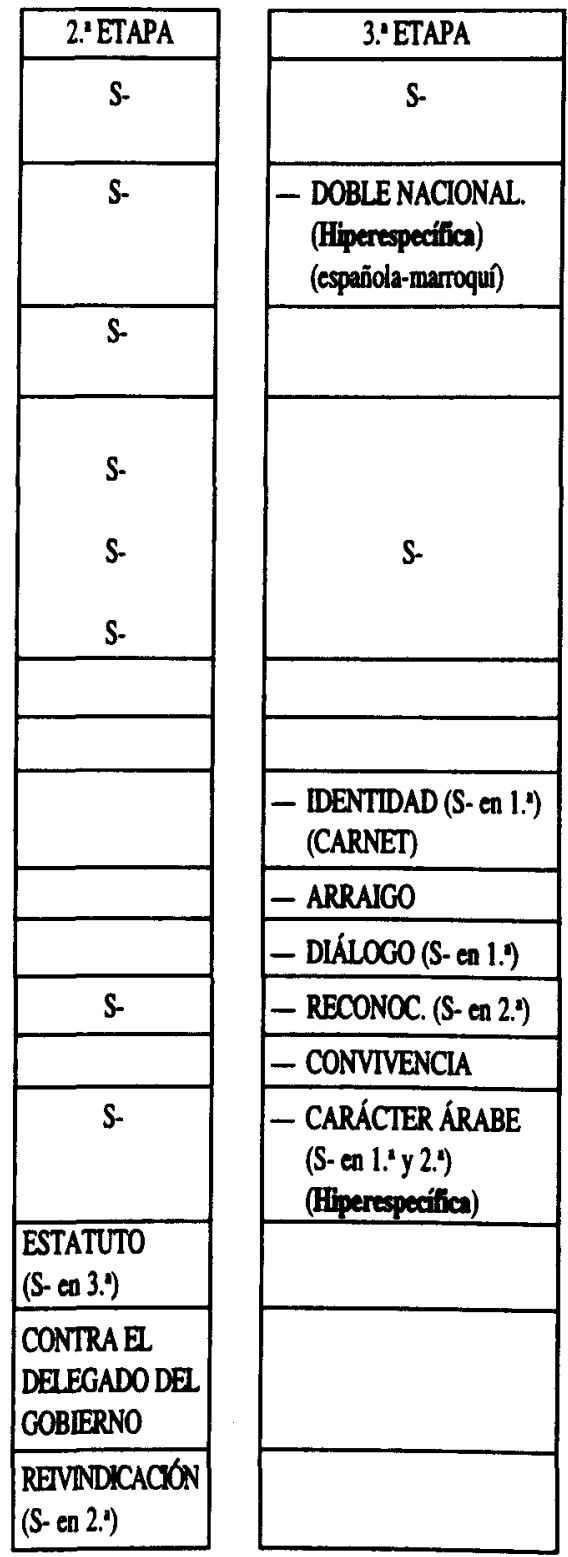

La aparición de l a urided designaliva indica que es expecificided postiva. (FIGURA 4) 
bitantes no musulmanes de Melilla: estatuto (S- en $3^{2}$ parte) ${ }^{11}$ y contra el delegado del gobierno. (Consúltese apartado 3 ). Recordemos que estatuto aparece como ultraempleada en El Alcázar.

\subsection{Red semíntica del aspecto patriótico}

En estos conflictos parece existir, de manera lingüísticamente velada, una exaltación, por parte de la derecha y ultraderecha, de la nación, España, frente a los musulmanes, los otros, que son extranjeros. Así se puede apreciar en los resultados de especificidad positiva en El Alcázar de las formas España, españoles, (la)nación, ejército y militar.

Destacan las especificidades negativas halladas en Melilla Hoy: español, española, (los) españoles, en España. Este hecho parece reflejar la no necesidad de este periódico de afianzarse en ningún calificativo o derivado de España, puesto que Melilla se considera y es España. Queda patente en el contexto «nuestra ciudad como parte integrante del estado español». En este periódico, el empleo del adjetivo española será como calificativo natural de sustantivos como nacionalidad, televisión, bandera, indicando la pertenencia al estado español. Las ocurrencias de españoles resultarán forzadas al recoger, en la crónica de información, los gritos de los cristianos en manifestaciones como «olé,ole, somos españoles». Sin embargo, este adjetivo englobará tanto a musulmanes como a cristianos cuando es el emisor el que se pronuncia. Esto se constata en los contextos «cuando nuestra dignidad como melillenses y españoles ha sido vejada. y por una Melilla unida y solidaria» o en «lo que nuestro gobierno ha hecho es oír a unos españoles que representan a unos colectivos que viven en dos ciudades» (Ceuta y Melilla). Aquí se está refiriendo a los re-

"El 27 de diciembre de 1985, el Consejo de Ministros aprueba los estatutos *especiales» para Ceuta y Melilla, que la mayoría de las fuerzas políticas de ambas ciudades (excepto PSOE) rechazan por considerar que no son estatutos de autonomía sino una especie de proyecto municipal.

La reivindicación de unos verdaderos estatutos de autonomía para ambas ciudades, asumida especialmente por la derecha (Alianza Popular, Coalición Popular, etc.) se va desarrollando, a lo largo del año, en paralelo con la lucha contra la aplicación de la Ley de Extranjería. El 29 de noviembre de 1986, el colectivo musulmán de Melilla hace público un documento en que se expone una serie de condiciones para negociar con el Gobierno, entre las cuales figura el establecer un estatuto especial para Melilla que garantizase el respeto y fomento de la cultura, creencias, tradiciones y lengua de los musulmanes.

El 5 de marzo de 1995, el Senado aprobo los estatutos de autonomía de Ceuta y Melilla, en cierto modo particulares, ya que la circunscripción del Ayuntamiento coincide con la de la Asamblea local. 
presentantes de los musulmanes. Este emisor, Melilla Hoy, prefiere melillense, resultando de especificidad positiva.

En plural, melillenses, es especificidad positiva también en El Pais, en las formas y poliformas (los) melillenses, a los melillenses, de los melillenses, melillenses de, para designar reiteradamente a los «melillenses musulmanes», a los «melillenses de origen marroquí 0 «de religión musulmana» y también a los cristianos, como se aprecia en «todo el colectivo de melillenses quiere que se mantenga el orden» o en «millones de melillenses se manifiestan para pedir la sustitución del delegado del gobierno». (Consúltese el empleo como designación de los sujetos socio-políticos).

\subsection{Manifestación de la alteridad}

En el análisis de los resultados de las designaciones de los sujetos sociopolíticos y de las formas y poliformas construidas con los adjetivos melillense y español, hemos detectado la diversa manera que tienen los distintos emisores de manifestar la alteridad, es decir, la diferenciación o no con respecto al кotro», en este caso, los musulmanes. A continuación, y con objeto de completar este estudio, vamos a examinar otras formas y poliformas léxicas y gramaticales que expresan la alteridad o, dicho de otro modo, la inclusión/exclusión.

Destaca el hecho de que la derecha y ultraderecha evita el léxico que netamente manifiesta la alteridad, como extranjeros, discriminación y racismo, formas que son subempleadas en El Alcázar, o racista también de especificidad negativa en $A B C$, mientras que El País ultraemplea discriminación y Diario 16 , racismo y minorías.

En contraste con lo anteriormente expuesto, si bien El País reconoce la existencia de dos comunidades (S+), se encuentra un afán o deseo integrador en Comunidad Musulmana y en Melilla Hoy. Así se aprocia en la forma todos y las poliformas todos los melillenses y todos los musulmanes ultraempleadas en Comunidad Musulmana y para todos de especificidad positiva en Melilla Hoy. Quizá esta tendencia queda reforzada por el mayor empleo de formas gramaticales indicativas de la inclusión del kotro», tanto en las especificidades positivas de las formas pronominales nos, nosotros, nuestra, nuestros, ultraempleadas en Melilla Hoy, como en el empleo de la $1^{2}$ persona del plural en estamos, vamos, sabemos y somos en el mismo periódico y, la última forma, tambien en Comunidad Musulmana.

Un análisis, desde la perspectiva cronologica, de las formas pertenecientes a estos agrupamientos semánticos resulta muy poco esclarecedor, quizá 
porque en cada etapa establecida están inmersos todos los emisores y, por tanto, las distintas ideologías que los gobiernan.

Tal vez lo único que podamos destacar en los resultados de la variable 3 ETAPAS es la proyección de la evolución del conflicto, que abarca desde el deseo de los musulmanes de ser españoles ( $S+$ en la $1^{*}$ etapa) hasta la proclamación por ellos mismos de una Melilla (magrebí) en la última etapa del corpus.

En numerosos contextos aparecen imbricados el patriotismo y la expresión de la alteridad. Así lo pudimos apreciar en el apartado 4.1., en enunciados emitidos por El Alcázar como «los marroquíes que viven en nuestro territorio nacional».

\section{ConClusiones}

Con la aplicación del método de las especificidades en dos variables distintas del corpus (7 EMISORES y 3 ETAPAS), se ha llegado a conseguir una notoria exhaustividad en los resultados finales, ya que los parciales obtenidos en cada variable se complementan mutuamente. Por tanto, como dice B.Habert $(1985,127)$ «Le programme [...] allie à la précision une grande richesse d'emploi.» [El programa [...] une a la precisión una gran riqueza de empleo.»

Así, del análisis de los resultados en la variable de 7 EMISORES, en que se ha procedido a un estudio del modo de distribución de las formas a través de los distintos emisores y, por consiguiente, comparando los resultados en los siete, hemos podido establecer las diferencias existentes entre los distintos emisores, así como apreciar la distancia ideológica que separa diarios como El Alcázar, por un lado, y El País o el conjunto de Comunidad Musulmana, en el extremo opuesto. Prácticamente podemos caracterizar ideológicamente a cada uno de los siete emisores.

Un hecho que debemos destacar, como de gran valía en el método lexicométrico empleado, es la posibilidad que ofrece de llegar a unos resultados bastante exactos sólo con limitarnos al análisis de los datos proporcionados por la aplicación del programa, aunque, lógicamente, se han de contrastar con la consulta constante del contexto. Esta consulta no sólo es necesaria para confirmar la veracidad o autenticidad de los resultados obtenidos sino que además, en muchos casos, proporciona información sobre la ideología de los sujetos sociopolíticos de los acontecimientos y no únicamente de los siete emisores de la prensa estudiada. Con ello se obtiene una nueva visión del texto completando de otra manera el aspecto cuantitativo con el cualitativo.

En la aplicación del método de las especificidades en la variable cronolo- 
gica ( 3 ETAPAS), en que hemos estudiado las formas en progresión y en regresión, se ha obtenido una nítida panorámica de la evolución del conflicto tratado por los siete emisores y no sólo del componente discursivo de la estrategia política llevada a cabo a lo largo de su desarrollo. No obstante, como apunta Peschanski (1981), al estar esta variable del corpus constituida en torno a fechas o etapas determinadas, no se efectúa una lectura continuada y, consecuentemente, algún momento concreto muy específico puede resultar subestimado. Nos preguntamos ¿hubiesen sido iguales los resultados si hubiéramos incluido, por ejemplo, la manifestación de los musulmanes, celebrada el día 26 de abril del mismo año, para protestar contra el racismo y reivindicar su cultura, su música, religión y lengua? A pesar de todo, la aplicación del método en esta variable cronológica nos ha permitido constatar el cambio de actitud de ciertos emisores, especialmente de la Comunidad Musulmana, con respecto a determinadas formas, aceptándolas o rechazándolas de su vocabulario.

Debemos señalar que el análisis de las formas pertenecientes a los agrupamientos semánticos confeccionados, también llevado a cabo en la variable de 7 EMISORES en la que nos ha proporcionado una gran riqueza interpretativa, por contra, ha resultado muy poco esclarecedor en la perspectiva cronológica, especialmente en determinadas redes semánticas.

En cualquier caso, una aportación incuestionable del método de las especificidades es, como señala B. Habert (1985), el hacer posible que hayamos validado las hipótesis sobre las posturas ideológicas de la prensa tratada.

Para finalizar diremos que este método lexicométrico, como hemos podido constatar en nuestro estudio, ofrece una gran abundancia de resultados, cuya precisión y valor de interpretación semántica sobresalen. El método es de gran utilidad en el análisis horizontal, en nuestro caso en la variable de los siete emisores, pero, además, se completa de manera que consideramos imprescindible, en su aplicación en la perspectiva cronológica.

\section{REFERENCIAS}

Gefrroy, A. (1980). «Trois successeurs de Marat pendant l'éte 1793: analyse lexicométrique des spécificités». Mots, 1, 167-187.

HABERT, B. (1985). «L'analyse des formes "spécifiques": bilan critique et proposition d'utilisation*. Mots, 11, 127-154.

LAFON, P. (1980). «Sur la variabilite de la fréquence des formes dans un corpus». Mots, 1, 127-165.

- (1981). «Statistiques des localisations des formes d'un texte». Mots, 2, 158-187.

La parole syndicale, BERGOUNIOUX, A.; LAUNAY, M-F.; MOURIAUX, R.; 
SUEUR, J-P.; TOURNIER, M. (1982). Paris: PUF.

PEsChanSKI, D. (1981). «Discours comuniste et "grand tournant". Étude des spécificités dans le vocabulaire communiste (1934-1936)». Mots, 2, 123-138.

SALEM, A. (1987). Pratique des segments répétés. Essai de statistique textuelle. Paris: Klinsieck.

TOURNIER, M. (1981). «Spécificité politique et spécificité lexicale». Mots, 2, 5-10. 